\title{
Pengaruh Penerapan Pendekatan Matematika Realistik Indonesia (PMRI) Terhadap Disposisi Matematika Siswa Pokok Bahasan Komposisi Dua Fungsi Dan Invers Fungsi Di Kelas XI IA-1 SMAN 4 Padangsidimpuan
}

\author{
Adek Safitri* \\ Email: adek@iain-padangsidimpuan.ac.id \\ Fakultas Tarbiyah dan Ilmu Keguruan IAIN Padangsidimpuan
}

\begin{abstract}
The objective of this study is to determine the effect of the application of the mathematical realistic approach toward the students' mathematics disposition. This study used a pre-experimental research design with a sample cluster random sampling technique. The experiment was conducted in SMA Negeri 4 Padangsidimpuan with the overall population of students of class XI IA second semester of the 2011/2012 academic year which consist of 5 classes as many as 163 students, while the sample of this study was class XI IA-1 which consist of 31 students. The instrument used the validated questionnaire. The experiment class was given pretest before treatment and posttest after treatment. Learning by using realistic mathematics approach provided significant influence on students' mathematical disposition. This was indicated by $\mathrm{t}$-test were obtained t-hitung = 9.8 and $t$-tabel $=2.042$. The data fulfilled the test of the hypothesis which is if $t-$ hitung $\geq \mathrm{t}$-tabel then $\mathrm{H}_{0}$ is rejected and $\mathrm{H}_{1}$ is accepted, which means there was a significant influence of the application of mathematical realistic approach Indonesia (PMRI) toward the students' mathematics disposition at class XI IA-1 SMAN 4 Padangsidimpuan.
\end{abstract}

Keywords: realiastic mathematic education, mathematic disposition, mathematics, composition of two functions, inverse functions

\footnotetext{
* Correspondence:

Email: adek@iain-padangsidimpuan.ac.id
} 


\begin{abstract}
Abstrak
Penelitian ini bertujuan untuk mengetahui pengaruh penerapan pendekatan matematika realistik terhadap disposisi matematika siswa. Penelitian ini menggunakan desain penelitian pre-eksperimen dengan teknik sampel cluster random sampling. Penelitian dilaksanakan di SMA Negeri 4 Padangsidimpuan dengan populasi keseluruhan siswa kelas XI IA semester genap tahun ajaran 2011/2012 yang terdiri dari 5 kelas sebanyak 163 siswa, sedangkan sampel penelitian ini adalah kelas XI IA-1 berjumlah 31 siswa. Instrumen menggunakan angket yang terlebih dahulu divalidasi. Kelas penelitian diberikan pretes sebelum perlakuan dan postes setelah perlakuan. Pembelajaran dengan menggunakan pendekatan matematika realistik memberikan pengaruh yang signifikan terhadap disposisi matematika siswa. Hal ini ditunjukkan dengan melakukan uji-t yang diperoleh $t_{\text {hitung }}=9,8$ dan $t_{\text {tabel }}=2,042$. Data tersebut memenuhi uji hipotesis yang menyatakan apabila $t_{\text {hitung }} \geq t_{\text {tabel }}$ maka $H_{0}$ ditolak dan $H_{1}$ diterima yang berarti terdapat pengaruh yang signifikan dari penerapan pendekatan matematika realistik Indonesia (PMRI) terhadap disposisi matematika siswa kelas XI IA-1 SMA Negeri 4 Padangsidimpuan.
\end{abstract}

Kata Kunci: pendekatan matematika realistik, disposisi matematika, matematika, komposisi dua fungsi, invers fungsi

\title{
A. PENDAHULUAN
}

Semakin berkembangnya ilmu pengetahuan dewasa ini mengakibatkan berbagai upaya dilakukan pemerintah untuk meningkatkan kualitas pembelajaran di sekolah. Upaya tersebut antara lain dengan melaksanakan sertifikasi guru sehingga guru mempunyai kompetensi pedagogik, kepribadian, professional, maupun kompetensi sosial yang telah diuji dan diakui serta mengoptimalkan pembelajaran dengan menyediakan fasilitas berupa pengadaan bahan-bahan ajar, media pembelajaran, dan sarana belajar lain seperti perpustakaan. Demikian pula tuntutan atas perkembangan matematika juga meningkat. Para ilmuwan terus memperbaharui konsep-konsep yang selama ini sudah ada sekaligus menemukan konsep-konsep lain sesuai perkembangan tersebut. Fungsi matematika sendiri sebagai ratu ilmu sains menjadikan matematika selalu digunakan dalam perkembangan ilmu-ilmu lain. Oleh karenanya, matematika dapat digunakan di segala bidang, maka matematika menjadi suatu pelajaran yang terus diperbaiki sistem pembelajarannya sejalan dengan itu matematika juga wajib dipelajari dan dipahami oleh siswa. Hal ini sesuai dengan tujuan umum diberikan matematika di 
jenjang persekolahan yaitu mempersiapkan siswa agar sanggup menghadapi perubahan keadaan di dalam kehidupan. ${ }^{1}$

Pengajaran matematika yang hanya berorientasi pada pemakaian rumus semata sudah harus ditinggalkan. Pengajaran matematika harus ditekankan pada eksplorasi dan investigasi matematika. Pengajaran dengan penekanan sistem tersebut akan membiasakan siswa untuk menggunakan ilmu pengetahuan dalam menyelesaikan berbagai persoalan matematika. Dengan demikian, disposisi matematika pun juga akan meningkat. Apabila kebiasaan berpikir matematika dan sikap menghargai kegunaan matematika seperti itu berlangsung secara berkelanjutan, maka secara akumulatif akan tumbuh disposisi matematika (mathematical disposition).

Guru matematika seharusnya lebih kreatif dalam menyampaikan berbagai materi pelajaran, karena banyak yang menganggap pelajaran matematika adalah pelajaran sulit. Matematika dianggap sulit karena sifatnya yang tidak konkrit, sehingga siswa merasa sulit untuk mempelajarinya. Hal ini dapat dibuktikan dari hasil analisis Programme for International Student Assesment (PISA) tahun 2012 yang mengukur kemampuan literasi membaca, matematika dan sains siswa berusia 15 tahun di SMP/MTs/SMA/MA/SMK, diperoleh skor Indonesia pada kemampuan matematika adalah 375 dari skor rata-rata 494. Hasil ini menunjukkan kemampuan matematika siswa di Indonesia masih dibawah standar Internasional. $^{2}$

Untuk itu sangat diharapkan adanya inovasi dalam pembelajaran matematika yang tidak hanya bertujuan pada penguasaan kemampuan pemahaman (understanding), penalaran (reasoning), pemecahan masalah (problem solving), komunikasi matematika (communicating) siswa, tapi juga mendorong tumbuhnya disposisi matematika siswa. Salah satu inovasi yang diharapkan mampu mewujudkan hal tersebut adalah pendekatan (approach) pembelajaran matematika. Pendekatan pembelajaran matematika adalah cara yang ditempuh guru dalam pelaksanaan pembelajaran agar konsep yang disajikan bisa beradaptasi. Oleh karena itu, pemakalah mencoba menggunakan pendekatan matematika realistik Indonesia (PMRI) dalam pelaksanaan pembelajaran.

\section{Disposisi Matematika}

Menurut National Council of Teachers Mathematics (NCTM) disposisi matematis: ${ }^{3}$ tidak hanya merujuk pada sikap akan tetapi kecenderungan untuk berpikir dan bertindak dalam cara yang positif. Disposisi matematika siswa merupakan manifestasi dalam cara mereka menyelesaikan tugas matematika baik hlm.9-10.

${ }^{1}$ Hasratuddin, Mengapa Harus Belajar Matematika (Medan: perdana Publishing, 2015),

2 PISA 2012. Result in Focus, What 15-year-olds knowm and why they can do with what they know. (OECD: Programme for International Student Assesment, 2013) hlm. 5

3 National Council of Teachers Mathematics. Principles and Standards for School Mathematics. (NCTM: Reston VA, 2000). 
dari kepercayaan diri, keinginan untuk mengeksplorasi cara alternatif, ketekunan dan ketertarikan, maupun kecenderungan untuk merefleksi cara berpikir mereka sendiri. Disposisi matematika lebih dari sekedar menyukai matematika. Siswa mungkin saja menyukai matematika tapi tidak mencerminkan sikap dan tindakan yang positif serta cara berpikir yang diharapkan. Bukti disposisi matematika telah dimiliki siswa dapat terlihat nyata pada latihan tertulis siswa seperti tugas rumah, proyek pengembangan, dan jurnal maupun presentasi secara lisan oleh siswa juga bisa menyediakan informasi berharga mengenai disposisi matematika siswa.

Disposisi matematis memuat tujuh komponen (NCTM: 2000), adapun ketujuh komponen-komponen itu sebagai berikut:

1. Percaya diri dalam menggunakan matematika,

2. Fleksibel dalam melakukan kerja matematika (bermatematika),

3. Gigih dan ulet dalam mengerjakan atau menyelesaikan tugas-tugas matematika,

4. Memiliki rasa ingin tahu dalam bermatematika,

5. Melakukan refleksi atas cara berpikir,

6. Menghargai aplikasi matematika, dan

7. Mengapresiasi peranan matematika.

Komponen-komponen disposisi matematis di atas termuat dalam kompetensi matematika dalam ranah afektif yang menjadi tujuan pendidikan matematika dengan memiliki sikap menghargai kegunaan matematika dalam kehidupan yaitu memiliki rasa ingin tahu, perhatian, dan minat dalam mempelajari matematika, serta sikap ulet dan percaya diri dalam pemecahan masalah.

Siswa yang telah memiliki disposisi matematika yang tinggi akan cenderung secara terus menerus terefleksi dalam cara mereka bertanya dan menjawab pertanyaan, bekerja dalam masalah, dan pendekatan yang baru mereka temukan. Karena bukti disposisi matematika dapat terlihat secara nyata pada latihan tertulis siswa seperti tugas rumah, proyek pengembangan, dan jurnal maupun presentasi secara lisan oleh siswa jugabias menyediakan informasi berharga mengenai disposisi matematika siswa. Seperti proyek individual atau presentasi kelompok mengenai solusi sebuah masalah atau pembuktian sebuah teorema bisa dijadikan bukti seberapa besar keinginan siswa untuk tekun dan teguh dalam mengerjakan tugas dan mencoba berbagai motede alternatif dalam menyelesaikan masalah. ${ }^{4}$

Jadi, dapat disimpulkan bahwa disposisi matematika yaitu keinginan, kesadaran, kecendrungan dan dedikasi yang kuat pada diri siswa atau mahasiswa untuk berfikir dan berbuat secara matematika.

${ }^{4}$ Safitri. Analisis Kemampuan Disposisi Matematika Siswa Kelas XII Keperawatan SMK Swasta Sartika Rantauprapat. (Prosiding seminar nasional pendidikan matematika HIPPMI, Medan, 21 Nopember 2015) 


\section{Pendekatan Matematika Realistik Indonesia}

Pendekatan dalam PMRI bertolak dari masalah-masalah kontekstual atau masalah yang dapat dibayangkan, siswa yang berperan aktif dalam pembelajaran sedangkan guru berperan sebagai fasilitator, siswa bebas untuk mengkomunikasikan ide-idenya satu sama lain dan guru membantu membandingkan ide-ide tersebut dan membimbing siswa mengambil keputusan tentang ide terbaik untuk mereka. Dengan ciri-ciri tersebut, maka PMRI memiliki prospek yang bagus diterapkan di Indonesia dibandingkan dengan pendekatan strukturalis, empiris, maupun mekanis. Harapan dan sikap optimis bahwa PMRI dapat merupakan jawaban terhadap beberapa problematika pembelajaran matematika di Indonesia.

Pendekatan matematika realistik sudah berkembang lebih dari 40 tahun pada bidang sains dan matematika. Activities from a unit to develop student understanding of logarithms are used to exemplify the RME design principle of progressive formalization. Starting from contexts that elicit students' informal reasoning, a series of representations and key questions were used to build connections between informal, pre-formal and formal representations of mathematics. Student and teacher comments from the pilot of this unit in a College Algebra course at a U.S. community college suggest this approach may benefit students who have been underserved by traditional approaches to mathematics instruction. ${ }^{5}$

Dalam RME Webb mengharapkan memperoleh hasil seperti berikut : "At the heart of RME is the didactical construct of progressive formalization. The "process of going from the concrete to the abstract" has been espoused in education psychology literature in the United States for at least a century (cf. Dewey, 1910) and can be traced back to $18^{\text {th }}$ century education-related writings in Europe (e.g., Rousseau, Pestalozzi, Froebel, Montessori, etc.). Yet, RME offers more than a way to support student transition from the concrete to the abstract. $R M E$ instructional sequences are conceived as "learning lines" in which problem contexts are used as starting points to elicit students' informal reasoning. That is, the context is a source for new mathematics".

Berbagai uraian diatas memberikan gambaran bahwa PMRI berpotensi untuk meningkatkan pemahaman matematika, keterampilan komputasi, serta kemampuan pemecahan masalah siswa. Dengan berbagai karakteristik yang dimiliki oleh PMRI Gravameijer seperti: ${ }^{6}$

\footnotetext{
${ }^{5}$ Webb, Design Research in the Netherlands: Introducing Logarithms Using Realistic Mathematics Education. (Netherland: University of Colorado at Boulder, 2011)

6 Gravemeijer, Developing realistic mathematics education. (Utrecht: Freudenthal Institute, 2010) hlm. 27-30.
} 
1. Penemuan terbimbing melalui proses matematisasi yang progresif. Penemuan terbimbing merupakan kegiatan pembelajaran yang melibatkan seluruh kemampuan berpikir siswa untuk mencari dan menyelidiki sesuatu secara sistematis, kritis, logis, analitis sehingga siswa dapat merumuskan sendiri apa yang ditemukannya dengan percaya diri. ${ }^{7}$

2. Menggunakan fenomena didaktikal.

Konsep fenomena didaktik merupakan fenomena/ konsep yang membantu guru mengaitkan antara materi yang diajarkan dengan situasi dunia nyata yang mendorong peserta didik membuat hubungan antara pengetahuan yang dimilikinya dengan penerapannya dalam kehidupan mereka sebagai anggota keluarga dan masyarakat. ${ }^{8}$

3. Pemodelan sendiri oleh siswa.

Pemodelan sendiri oleh siswa merupakan jembatan bagi siswa dari situasi riil ke situasi konkrit atau dari informal matematika ke formal matematika. Artinya siswa membuat model sendiri dalam menyelesaikan masalah. Pada awalnya siswa akan mengembangkan model yang familiar bagi mereka. Dengan generalisasi dan formalisasi secara berangsur-angsur model tersebut akan menjadi sebuah kesatuan.

Sementara itu, terdapat lima prinsip utama pembelajaran yang berorientasi PMRI, yaitu:

1. Penggunaan masalah kontekstual,

2. Penggunaan model untuk matematisasi progresif,

3. Pemanfaatan hasil konstruksi siswa,

4. Interaktivitas,

5. Keterkaitan antar konsep matematika.

Menurut Paul Dickinson and Sue Hough RME memberikan efek "Teachers using RME report that it enables more students to understand mathematics and to engage with it. However, it is not easy to measure the effectiveness of a way of teaching, particularly when its aims are not quite the same as those in conventional classrooms. (RME places more emphasis on understanding and problem solving)". 9

The study Palinussa found that: 1) Achievements and enhancement of students' critical mathematical thinking skills who were treated with by realistic

7 Ahmadi, Strategi Pembelajaran Berorientasi KTSP. (Jakarta: Prestasi Pustakarya, 2011), hlm. 115-116

${ }^{8}$ Suprijono, Cooperative Learning Teori \& Aplikasi PAIKEM.(Yogyakarta: Pustaka Pelajar, 2009), hlm.9

9 Dickinson, Using Realistic Mathematics Education in UK classrooms. (Manchester, United Kingdom: Manchester Metropolitan University, 2012), hlm. 54. 
mathematics education is better then students' skills were treated by conventional mathematics education. The differences are considered to: a) overall students, $b$ ) the level of early math skills, and c) schools' level; 2) Quality of students' character who were treated by realistic mathematics education is better then students' character who were treated by conventional mathematics education The differences are considered to: a) overall students, b) the level of early math skills, and c) schools' level. ${ }^{10}$

This study Arsaythamby showed that Mathematics activities for those who were taught using RME are higher than for those using the conventional approach. The results showed that RME approach is being practised in Aceh, but not completely. The higher percentage of activities suggests that the Aceh Education Office expands the implementation of RME in all primary schools so that learning of Mathematics is more effective. ${ }^{11}$

Oleh karena itu, kaitan antara PMRI dengan disposisi matematika siswa adalah bahwa disposisi siswa akan lebih cepat muncul dan berkembang jika persoalan matematika diangkat dari kehidupan nyata karena disposisi matematika juga menuntut agar dapat mengaplikasikan pengetahuan matematikanya terhadap kehidupan sehari-hari. Jadi, keduanya saling berkaitan.

Salah satu materi yang sulit bagi siswa untuk mengetahui kegunaan dan aplikasinya dalam kehidupan sehari-hari adalah komposisi dua fungsi dan invers fungsi, topik yang saat itu mereka pelajari.Mereka menganggap topik tersebut tidak berguna bagi kehidupan sehari-hari sehingga tidak perlu dipelajari. Oleh karena itu, maka peneliti mengambil topik komposisi dua fungsi dan invers fungsi sebagai materi penelitian.

\section{B. METODE}

1. Populasi dan Sampel

Populasi penelitian ini adalah seluruh siswa kelas XI IA SMA Negeri 4 Padangsidimpuan. Sampel dipilih melalui teknik cluster random sampling yaitu kelas XI IA-1 SMA Negeri 4 Padangsidimpuan.

2. Desain Penelitian

Jenis penelitian yang digunakan adalah penelitian pre-eksperimen. Penelitian pre-eksperimen adalah penelitian yang tidak memiliki kelas kontrol. Jadi, hanya ada satu kelas saja yang menjadi perhatian peneliti. Penelitian pre-

\footnotetext{
${ }^{10}$ Palinussa, Students Critical Mathematical Thinking Skills and Character: Experiments for Junior High School Students through Realistic Mathematics Education Culture-Based”. (IndoMS. J.M.E, 2013)

${ }^{11}$ Arsaythamby, How A Realistic Mathematics Educational Approach Affect Students' Activities In Primary Schools?. (Malaysia, Universiti Utara Malaysia, 2014)
} 
eksperimen dilakukan untuk mengetahui apakah disposisi matematika siswa kelas XI IA-1 SMAN 4 Padangsidimpuan meningkat setelah menggunakan pembelajaran berbasis PMRI. Pendekatan yang digunakan adalah kuantitatif.

3. Instrumen Penelitian

Instrumen yang digunakan dalam penelitian ini adalah angket untuk mengetahui tumbuh atau tidaknya disposisi matematika siswa kelas XI IA-1 SMA Negeri 4 Padangsidimpuan. Tes terlebih dahulu divalidasi dan dilakukan uji coba di kelas uji coba.

4. Teknik Analisis Data

Data yang diperoleh dari nilai siswa sebelum dan sesudah menerapkan PMRI adalah dengan menghitung skor yang diperoleh siswa di kelas eksperimen dalam angket. Pengolahan data diawali dengan menguji persyaratan statistik yang diperlukan yaitu uji normalitas dan uji t sebagai salah satu teknik statistik inferensial yang memiliki misi mengambil kesimpulan secara umum.

\section{HASIL PENELITIAN DAN PEMBAHASAN}

\section{Hasil Penelitian}

Penelitian yang dilakukandi SMA Negeri 4 Padangsidimpuan dengan mengambil sampel satu kelas yaitu kelas XI IA -1 sebagai kelas eksperimen yang terdiri dari 31 siswa. Penelitian ini menggunakan pendekatan matematika realistik Indonesia (PMRI). Tujuan utama penelitian ini adalah untuk mengetahui pengaruh penerapan pendekatan matematika realistik Indonesia terhadap disposisi matematika siswa.

Tabel 1 : Perbandingan nilai Pretest dan Posttest Siswa kelas XI IA-1 SMA N 4 Padangsidimpuan

\begin{tabular}{cccccc}
\hline NO. & NAMA SISWA & $\begin{array}{c}\text { Nilai } \\
\text { Pretest }\end{array}$ & $\begin{array}{c}\text { Nilai } \\
\text { Posttest }\end{array}$ & $\begin{array}{c}\text { Gain (d) (posttest } \\
- \text { pretest) }\end{array}$ & $d^{2}$ \\
\hline 1 & AIL & 60 & 85 & 25 & 625 \\
\hline 2 & AAS & 60.6 & 84.38 & 23.78 & 565.488 \\
\hline 3 & AT & 70 & 81.25 & 11.25 & 126.563 \\
\hline 4 & Atjg & 65 & 75 & 10 & 100 \\
\hline 5 & BML & 70 & 75 & 5 & 25 \\
\hline 6 & DR & 60 & 85 & 25 & 625
\end{tabular}




\begin{tabular}{|c|c|c|c|c|c|}
\hline 7 & EA & 77.5 & 88.13 & 10.63 & 112.997 \\
\hline 8 & HT.N.S & 80 & 84.38 & 4.38 & 19.1844 \\
\hline 9 & IMRP & 75 & 82.5 & 7.5 & 56.25 \\
\hline 10 & IWH & 75 & 82.5 & 7.5 & 56.25 \\
\hline 11 & $\mathrm{JH}$ & 66.9 & 90 & 23.1 & 533.61 \\
\hline 12 & $\mathrm{MSH}$ & 65 & 75 & 10 & 100 \\
\hline 13 & MSS & 65 & 75 & 10 & 100 \\
\hline 14 & $\mathrm{MSN}$ & 75 & 75 & 0 & 0 \\
\hline 15 & MYT & 62.5 & 87.5 & 25 & 625 \\
\hline 16 & NRNS & 64.4 & 87.5 & 23.1 & 533.61 \\
\hline 17 & NSS & 66.3 & 88.75 & 22.45 & 504.003 \\
\hline 18 & Nni & 75 & 81.25 & 6.25 & 39.0625 \\
\hline 19 & NS & 80 & 87.5 & 7.5 & 56.25 \\
\hline 20 & OKDM & 65 & 75 & 10 & 100 \\
\hline 21 & RMWT & 65 & 84.38 & 19.38 & 375.584 \\
\hline 22 & RA & 75 & 80 & 5 & 25 \\
\hline 23 & RARS & 76.3 & 80 & 3.7 & 13.69 \\
\hline 24 & $\mathrm{RH}$ & 65 & 75 & 10 & 100 \\
\hline 25 & RAH & 60 & 75 & 15 & 225 \\
\hline 26 & RSD & 60 & 75 & 15 & 225 \\
\hline 27 & SJS & 70 & 80 & 10 & 100 \\
\hline 28 & TAH & 60 & 75 & 15 & 225 \\
\hline 29 & YSS & 70 & 80 & 10 & 100 \\
\hline 30 & YP & 75 & 90 & 15 & 225 \\
\hline 31 & ZMS & 75 & 84.38 & 9.38 & 87.9844 \\
\hline & nlah & 2129.5 & 2524.4 & 394.9 & 6605.53 \\
\hline
\end{tabular}


a) Hasil Tes Disposisi Matematika Kelas Eksperimen

Tabel 2: Hasil Tes Disposisi Matematika Kelas Eksperimen

\begin{tabular}{ccccccc}
\hline $\begin{array}{c}\text { Kelas } \\
\text { Eksperimen }\end{array}$ & Skor Maksimal & $X_{\text {maks }}$ & $X_{\min }$ & $X_{\text {rata-rata }}$ & SD & Uji t \\
\hline Pretes & 160 & 80 & 60 & 69 & 6,2 & \multirow{2}{*}{ (16,8 } \\
Postes & 160 & 90 & 75 & 79 & 5 & \\
\hline
\end{tabular}

Dari tabel diatas dapat diambil kesimpulan bahwa rata-rata peningkatan disposisi matematika sebelum dan sesudah pembelajaran dengan PMRI lebih tinggi maka dapat dinyatakan peningkatan yang terjadi adalah signifikan.

b) Deskripsi Hasil Tes Disposisi Matematikan Kelas Eksperimen

Secara garis besar untuk hasil tes disposisi matematika pada kelas eksperimen dapat dilihat pada tabel 1, tampak bahwa dari pretes diperoleh skor tertinggi 80, skor terendah 60, rata-rata 69 dan standar deviasi ssebesar 6,2. Sedangkan untuk postes diperoleh skor tertinggi 90 , skor terendah 75 , rata-rata 79 dan standar deviasi sebesar 5 serta hasil uji t sebesar 9,8.

Dari deskripsi tersebut dapat menunjukkan bahwa terdapat peningkatan disposisi matematika siswa pada kelas eksperimen.

\section{Pembahasan Hasil Penelitian}

Mencermati hasil penelitian yang telah dikemukakan diatas, menunjukkan bahwa pembelajaran dengan pendekatan matematika realistik memiliki pengaruh yang signifikan terhadap diposisi matematika siswa. Secara teoritis pembelajaran dengan pendekatan matematika realistik memiliki beberapa keunggulan, yaitu sebagai berikut:

1. Mengubah sikap siswa menjadi lebih tertarik terhadap matematika.

2. PMRI memberikan masalah yang berkaitan dengan kehidupan sehari-hari dan pembelajarannya tidak formal.

3. Siswa merasa tertantang dan bersemangat mengerjakan soal karena banyak permainan, gambar/simbol yang dapat membantu sehingga matematika lebih mudah.

4. PMRI memberikan pengertian yang jelas dan operasional kepada siswa bahwa proses pembelajaran merupakan sesuatu yang utama.

5. PMRI memadukan kelebihan-kelebihan dari berbagai pendekatan pembelajaran.

Selanjutnya, untuk pembahasan hasil penelitiannya berdasarkan uji normalitas dan uji t data peningkatan disposisi matematika pada kelas eksperimen yaitu kelas XI IA-1 SMA Negeri 4 Padangsidimpuan diperoleh nilai t hitung 
adalah 9,8 dan signifikansi 0,000. T tabel dapat dilihat pada tabel statistik pada signifikansi $0,05: 2=0,025$ dengan derajat kebebasan (df) $n-1$ atau 31-1 $=30$. Hasil yang diperoleh untuk t tabel sebesar 2,042. Oleh karena itu, nilai t hitung adalah 9,8 lebih besar daripada nilai t tabel yaitu sebesar 2,042.

Jika $t_{\text {hitung }} \geq t_{\text {tabel }}$, maka Ho ditolak

Jika $t_{\text {hitung }}<t_{\text {tabel }}$, maka Ho diterima

Berdasarkan signifikansi:

Jika signifikansi $>0,05$ maka Ho diterima

Jika signifikansi $<0,05$ maka Ho ditolak

Karena nilai $t_{\text {hitung }} \geq t_{\text {tabel }}(9,8 \geq 2,042)$ dan signifikansi $<0,05(0,000<$ 0,05), maka Ho ditolak. Jadi, dapat disimpulkan bahwa terdapat perbedaan ratarata nilai tes antara sebelum dan sesudah PMRI.Pengambilan taraf signifikan dalam penelitian ini adalah 95\%, penarikan kesimpulan dapat dipercaya sebesar 95\% dan penarikan kesimpulan kemungkinan salah hanya 5\%.

Hal ini dapat diartikan bahwa terdapat pengaruh yang signifikan dari penerapan pendekatan matematika realistik Indonesia (PMRI) terhadap disposisi matematika siswa pokok bahasan komposisi dua fungsi dan invers fungsi di kelas XI IA-1 SMA Negeri 4 Padangsidimpuan. Penelitian ini menunjukkan bahwa PMRI memilki nilai rata-rata pretes-postes yang lebih baik untuk diterapkan daripada tidak adanya penerapan PMRI terhadap disposisi matematika siswa kelas XI IA-1 SMA Negeri 4 Padangsidimpuan. Dan hal ini berlaku secara umum.

\section{KESIMPULAN}

Berdasarkan hasil penelitian dapat diambil kesimpulan yang relevan dengan penelitian ini, antara lain:

1. Siswa lebih aktif dalam proses pembelajaran dengan menggunakan PMRI dibandingkan tanpa menggunakan PMRI (pendekatan tradisional).

2. Disposisi matematika siswa kelas XI IA-1 SMA Negeri 4 Padangsidimpuan muncul dan berkembang setelah menggunakan PMRI. Hal ini dapat dilihat pada rata-rata kelas yang diperoleh sebelum dan setelah menggunakan PMRI. Rata-rata kelas sebelum menggunakan PMRI 70,00 sedangkan rata-rata kelas setelah menggunakan PMRI menjadi 78,95 .

3. Hasil pengujian hipotesis menunjukkakan bahwa penggunakan PMRI terhadap disposisi matematika siswa lebih baik setelah menggunakan PMRI. Dengan kata lain, ada pengaruh yang signifikan dalam 
pembelajaran dengan menggunakan PMRI terhadap disposisi matematika siswa kelas XI IA-1 SMA Negeri 4 Padangsidimpuan.

Berdasarkan kesimpulan diatas, ada beberapa saran yang perlu disampaikan sehubungan dengan pelaksanaan penelitian ini, yaitu sebagai berikut:

1. Kepada guru, disarankan kepada guru bidang studi agar mengubah metode dan strategi/ pendekatan pembelajaran yang selama ini diterapkan, disarankan untuk menggunakan pendekatan matematika realistik Indonesia.

2. Kepada siswa, disarankan kepada siswa untuk aktif dalam proses pembelajaran dan menumbuh kembangkan disposisi matematika siswa.

3. Kepada kepala sekolah, hendaknya dapat menyarankan agar para guru bidang studi menerapkan pendekatan matematika realistik Indonesia (PMRI) supaya siswa bisa aktif dalam pembelajaran dan mampu mengaitkan antara pengetahuan yang dimilikinya dengan kehidupan nyata.

\section{DAFTAR PUSTAKA}

Adek Safitri, Analisis Kemampuan Disposisi Matematika Siswa Kelas XII Keperawatan SMK Swasta Sartika Rantauprapat, Prosiding seminar nasional pendidikan matematika HIPPMI, Medan, 21 Nopember 2015.

Ahmadi, Lif Khoiru, dkk., Strategi Pembelajaran Berorientasi KTSP, Jakarta: Prestasi Pustakarya, 2011.

Arsaythamby, V., How A Realistic Mathematics Educational Approach Affect Students' Activities In Primary Schools?, Malaysia, Universiti Utara Malaysia, 2014.

Barnes, Heyley, Realistic Mathematics Education: Eliciting Alternative Mathematical Conceptual Conceptions of Learners. African journal of Reasearch in SMT Education, 2004.

Dickinson, Paul and Sue Hough, Using Realistic Mathematics Education in UK classrooms, Manchester, United Kingdom: Manchester Metropolitan University, 2012.

Farikhin. Mari Berpikir Matematis. Yogyakarta: Graha Ilmu, 2007. 
Fauzan, Ahmad, Applying Realistic Mathematics Education in Teaching Geometry in Indonesian Primary Schools. Netherlands: University of Twente, 2002.

Gravemeijer, K., Developing realistic mathematics education. Utrecht: Freudenthal Institute, 2010.

Hasratuddin, Mengapa Harus Belajar Matematika?. Medan: perdana Publishing, 2015.

National Council of Teachers Mathematics, Evaluation: Standard 10: Mathematichal Disposition, NCTM: Reston VA, 1989.

National Council of Teachers Mathematics. "Principles and Standards for School Mathematics". NCTM: Reston VA, 2000.

Palinussa, Anderson L., Students Critical Mathematical Thinking Skills and Character: Experiments for Junior High School Students through Realistic Mathematics Education Culture-Based, IndoMS. J.M.E, 2013.

PISA 2012, Result in Focus, What 15-year-olds knowm and why they can do with what they know, OECD: Programme for International Student Assesment, 2013.

Saputra, Edi, Meningkatkan Kemampuan Spasial dan Disposisi Matematika Siswa SMP dengan Pendekatan PMRI pada Pembelajaran Geometri Berbantuan Komputer, Bandung: UPI, 2010.

Suherman, Erman dkk, Strategi Pembelajaran Matematika Kontemporer, Bandung: UPI, 2001.

Sumarmo, Utari, Berfikir dan Disposisi Matematik: Apa, Mengapa dan Bagaimana Dikembangkan, 2010.

Suprijono, Agus. "Cooperative Learning Teori \& Aplikasi PAIKEM". Yogyakarta: Pustaka Pelajar, 2009.

UZEL, Devrim, Attitudes of 7th Class Students Toward Mathematics in Realistic Mathematics Education, Turkey, Department of Mathematics Education Balıkesir University, 2006. 
Webb, David C. et.el., Design Research in the Netherlands: Introducing Logarithms Using Realistic Mathematics Education, Netherland: University of Colorado at Boulder, 2011.

Wijaya, Ariadi, Pendekatan Matematika Realistik, Yogyakarta: Graha Ilmu, 2012. 